\title{
Enhanced recovery in colorectal surgery: a multicentre study
}

\author{
José M Ramírez ${ }^{1}$, Juan A Blasco², José V Roig ${ }^{3}$, Sergio Maeso-Martínez ${ }^{2 *}$, José E Casall, Fernando Esteban ${ }^{5}$, \\ Daniel Callejo Lic ${ }^{2}$ and for Spanish working group on fast track surgery
}

\begin{abstract}
Background: Major colorectal surgery usually requires a hospital stay of more than 12 days. Inadequate pain management, intestinal dysfunction and immobilisation are the main factors associated with delay in recovery. The present work assesses the short and medium term results achieved by an enhanced recovery program based on previously published protocols.
\end{abstract}

Methods: This prospective study, performed at 12 Spanish hospitals in 2008 and 2009, involved 300 patients. All patients underwent elective colorectal resection for cancer following an enhanced recovery program. The main elements of this program were: preoperative advice, no colon preparation, provision of carbohydrate-rich drinks one day prior and on the morning of surgery, goal directed fluid administration, body temperature control during surgery, avoiding drainages and nasogastric tubes, early mobilisation, and the taking of oral fluids in the early postoperative period. Perioperative morbidity and mortality data were collected and the length of hospital stay and protocol compliance recorded.

Results: The median age of the patients was 68 years. Fifty-two \% of the patients were women. The distribution of patients by ASA class was: I 10\%, || 50\% and III 40\%. Sixty-four \% of interventions were laparoscopic; 15\% required conversion to laparotomy. The majority of patients underwent sigmoidectomy or right hemicolectomy. The overall compliance to protocol was approximately $65 \%$, but varied widely in its different components. The median length of postoperative hospital stay was 6 days. Some 3\% of patients were readmitted to hospital after discharge; some $7 \%$ required repeat surgery during their initial hospitalisation or after readmission. The most common complications were surgical (24\%), followed by septic (11\%) or other medical complications (10\%). Three patients (1\%) died during follow-up. Some $31 \%$ of patients suffered symptoms that delayed their discharge, the most common being vomiting or nausea (12\%), dyspnoea (7\%) and fever (5\%).

Conclusion: The following of this enhanced recovery program posed no risk to patients in terms of morbidity, mortality and shortened the length of their hospital stay. Overall compliance to protocol was $65 \%$. The following of this program was of benefit to patients and reduces costs by shortening the length of hospital stay. The implantation of such programmes is therefore highly recommended.

\section{Background}

Major colorectal surgery, i.e., surgery that involves wide resection of the colon and anastomosis, generally involves a prolonged hospital stay - on average 12-14 days. A stay of one week is usually the minimum that can be expected [1]. This prolonged occupation of a hospital bed is not usually owed to problems of

\footnotetext{
* Correspondence: smaemar@hotmail.com

${ }^{2}$ Health Technology Assessment, Agencia Laín Entralgo, Madrid, Spain

Full list of author information is available at the end of the article
}

morbidity but to the conventional care protocol followed. For decades this protocol has hardly been modified: it therefore does not take into account the advances that have been made in the perioperative management of such patients.

Inadequate pain management, intestinal dysfunction and immobilisation have been recognised since at least 1997 as among the main factors delaying postoperative recovery in patients subjected to major surgery [2]. This led Kehlet et al [3] to propose a series of measures designed to improve recovery following major colorectal

\section{Biomed Central}


surgery in their well-known multimodal recovery program. Currently, evidence-based multidisciplinary action protocols of this kind, known initially as fast-track or better called enhanced recovery programs (ERAS), are not achieving the degree of implantation hoped for [3]. Some authors suggest this to be due to the organisational demands they make on surgeons, anaesthetists and nursing staff, and to social, cultural and economic realities [4].

The results that can be achieved with ERAS - reductions in postoperative morbidity, average length of hospital stay and the consumption of resources - are, however, significant, and the general implantation of an ERAS for patients who are to undergo colorectal surgery is recommendable [5-8]. In some of the clinical practice guides available at http://www.reducinglengthofstay.org/, these programmes are considered to represent best clinical practice according to current scientific evidence. Unfortunately, the results communicated regarding surgery in an ERAS context have nearly all come from individual institutions, although they include those of four randomised clinical trial [5,9-11]. Recently the results of an international study (five hospitals in different countries, four with no prior experience in ERAS) reporting on patient follow-up, the degree of acceptance and the degree of compliance with the protocol of a common ERAS, have also become available [12]. The results of these studies [5,9-12] suggest that just making a protocol available is insufficient for objectives to be achieved; changes also need to be made to organisational strategies and the medical professionals involved in pre, intra and especially postoperative care require support, perhaps via continuing education.

The present work analyses the short and medium term results returned by an ERAS for colorectal surgery based on previously published protocols, followed at 12 Spanish hospitals.

\section{Methods}

\section{Participating centres}

The twelve participating centres were chosen for their organisational abilities and their experience and interest in colorectal surgery and patient care. These centres, distributed around Spain, ranged from large university hospitals to medium and small area hospitals (the Clínico from Zaragoza, La Paz, Clínico San Carlos and Gregorio Marañón from Madrid, General from Valencia, Mútua Terrassa, Do Meixoeiro from Vigo, Hospital d'Igualada, La Mancha Centro from Alcázar de San Juan, Universitario de Elche, Son Llatzer from Palma de Mallorca and Fundación Calahorra hospitals) with the collaboration of Health Technology Assessment Unit from Agencia Laín Entralgo, Madrid.
There were two meetings with at least two professionals of each centre, a surgeon and an anaesthetist. During these meetings discussions were held with national and international experts who assisted the group in the implementation of the program. These professionals were the persons in charge to develop the program in their centre and to starting the implementation of the protocol in two months after the second work session. There were two annual reunions with the group to supervise and improve the compliance of the protocol.

\section{Study design}

This prospective study, which involved 300 patients, was performed between 2008 and 2009. The ERAS used was developed by the authors on the basis of published protocols $[3,5,8-12]$. The variables recorded included perioperative mortality, length of hospital stay and compliance with the protocol.

The study was presented to the Hospital Ethical Board and accepted as this is an observational non-randomised study based on the best available evidence.

The research was conducted conformed to the Helsinki Declaration and to local legislation. Patients gave informed consent to participate in the study. This study has been registered in the ISRCTN register with the number ISRCTN16397735, you can also access to the registration information by the URL: http://www.controlled-trials.com/ISRCTN16397735.

\section{Inclusion and exclusion criteria}

A) Inclusion criteria. All patients had to be 18 years of age or over and to be programmed for surgery for colorectal cancer without the need for a stoma or any further surgical procedure.

B) Exclusion criteria: The need for emergency surgery, an American Society of Anaesthesiologists (ASA) class of IV, the need for a colostomy or ileostomy, the inability to provide informed consent, diabetes, slow evacuation previously documented by a digestive medicine unit.

\section{Enhanced recovery program protocol}

The ERAS required that, during the preoperative period, patients be given advice, that there be no preparation of the colon and that patients receive four carbohydraterich drinks $(4 \times 200 \mathrm{ml})$ one day prior to surgery plus two further drinks $(2 \times 200 \mathrm{ml})$ on the morning of surgery. During surgery, goal directed fluids were administered using oesophageal Doppler monitoring, and hypothermia and drainages avoided. After surgery, nasogastric tubes were not used, early mobilisation was practised, and oral fluids administered early. Table 1 
Table 1 Protocol characteristics of the followed enhanced recovery program

\begin{tabular}{|c|c|}
\hline Time & Procedure \\
\hline \multirow[t]{2}{*}{ Preoperative } & a. Provision of verbal and written information to patients regarding the ERAS. Collection of signed consent. \\
\hline & b. Malnourished patients to receive hyperproteic supplement at least twice per day during the week before surgery. \\
\hline \multirow[t]{4}{*}{ Day before surgery } & a. No colon preparation. \\
\hline & $\begin{array}{l}\text { b. Normal food in the morning. Liquids on demand during the evening. Four bricks of carbohydrate-rich Nutricia Preop } \\
\text { to be taken during the evening (total: } 800 \mathrm{ml} \text { ). }\end{array}$ \\
\hline & c. Prophylaxis for pulmonary thromboembolism following normal practice. \\
\hline & d. Antibiotic prophylaxis following normal practice. \\
\hline \multirow{2}{*}{$\begin{array}{l}\text { Day of surgery (before } \\
\text { surgery) }\end{array}$} & a. Two hours before surgery: provision of two bricks of Nutricia Preop ${ }^{\mathbb{B}}$ (total: $400 \mathrm{ml}$ ). \\
\hline & b. Antibiotic prophylaxis. \\
\hline \multirow[t]{11}{*}{ Operating room } & $\begin{array}{l}\text { A. Surgeons: no drainage; nasogastric tube, if needed, to be removed before extubation; if possible use transverse or } \\
\text { curved incisions in open surgery. }\end{array}$ \\
\hline & B Anaesthetists: \\
\hline & -Maintenance: Oxygen/air with FiO2 >80\%. \\
\hline & -Monitoring: routine. Only use arterial/central catheter if unavoidable. \\
\hline & -Fluids: maintenance with Hartmann ( $5 \mathrm{cc} / \mathrm{kg} / \mathrm{h}$ ). Bolus of gelofusine (250 cc). \\
\hline & Maintain $\mathrm{Hb}>8.0 \mathrm{~g} / \mathrm{dl}$. \\
\hline & - Optimise stroke volume via oesophageal Doppler: \\
\hline & $\begin{array}{l}-250 \text { cc of fluid in bolus; if SV > 10\% repeat until this figure is not reached. Provide no further bolus unless SV falls or } \\
\text { there is blood loss. }\end{array}$ \\
\hline & -If hypotension remains after SV correction, use a vasoconstrictor. \\
\hline & -Consider use of inotropic agents if peak velocity descends and clinical signs suggest ventricular function deficit. \\
\hline & -Temperature: use liquid heater and heating blanket. \\
\hline \multirow{2}{*}{$\begin{array}{l}\text { Day of surgery (recovery } \\
\text { room) }\end{array}$} & -Mask with high oxygen flow for $2 \mathrm{~h}$ independent of saturation. Follow with nasal cannulae to maintain SpO2 > 95\%. \\
\hline & -Maintain mean blood pressure $>65 \mathrm{mmHg}$. If blood pressure low provide $250 \mathrm{cc}$ gelofusine and reassess. \\
\hline \multirow[t]{4}{*}{ Day of surgery (ward) } & -In the evening sit patient in seat for at least $2 \mathrm{~h}$. \\
\hline & $\begin{array}{l}\text {-Liquid diet (800-1000 ml). Include two bricks of high protein/high calorie hospital dietary preparation (specific for } \\
\text { postoperative period). }\end{array}$ \\
\hline & -Minimum diuresis (500 cc in first $24 \mathrm{~h}$ ). \\
\hline & -Analgesia: $1 \mathrm{~g}$ paracetamol/6 h. \\
\hline \multirow[t]{7}{*}{ Postoperative day 1} & -Liquid diet, at least $2 \mathrm{l}$, including 3 bricks of high protein/high calorie hospital dietary preparation. \\
\hline & -Mobilisation; patient seated at least $6 \mathrm{~h}$ per day. \\
\hline & -Suspend IV fluid if tolerated. Heparin injection for maintaining patency of intermittent infusion devices. \\
\hline & -Maintain epidural analgesia pump if one in place. \\
\hline & -Paracetamol $1 \mathrm{~g} / 6 \mathrm{~h}$. \\
\hline & -Lactulose 1 sachet/12 h (preferably magnesium-based). \\
\hline & $\begin{array}{l}\text {-Assess meeting of discharge criteria: only oral analgesia, mobilisation reaching presurgical level, toleration of solid food, } \\
\text { gases passed, stools passed, no nausea, and patient agrees to discharge. }\end{array}$ \\
\hline Postoperative day 2 & $\begin{array}{l}\text {-Suspend epidural catheter; begin with NSAIDS; diet soft/normal; mobilisation on demand; remove urinary catheter and } \\
\text { assess meeting of discharge criteria. }\end{array}$ \\
\hline Postoperative day 3 & -Check general status; assess meeting of discharge criteria and take decision in this respect. \\
\hline \multirow[t]{2}{*}{ Follow up } & -Telephone monitoring for $48 \mathrm{~h}$. \\
\hline & -First out-patient visit 10-14 days after surgery. \\
\hline
\end{tabular}

SV: stroke volume; IV: intravenous; Hb: haemoglobin.

summarises the protocol characteristics of the ERAS followed.

Although not explicitly required by the ERAS, the following variables were also recorded: opioid-free pain control, the use of prophylactic medication for postoperative vomiting and nausea, and the use of epidural anaesthesia.

Patients were discharged following the criteria established by the ERAS protocol. All patients were followedup for at least three months. 
An online database http://www.ftsurgery.com/ was prepared for the collection of data from the different centres.

\section{Data analysis}

Dichotomous variables were recorded as absolute frequencies (number of cases) and relative frequencies (percentages). It should be noted that this work reports frequencies and percentages with respect to the data made available; therefore they do not always refer to all patients. Continuous variables were recorded as means and standard deviations (SD) or median plus maximum and minimum values, depending on whether or not their distribution was normal (determined by the Kolmogorov-Smirnov test). All analyses were made using 18 version SPSS software.

\section{Results}

Patients, surgery and postoperative treatment

Of all patients who initially met criteria for inclusion, 16 were excluded, 9 patients were in intensive care at the discretion of the anaesthetist and 7 received an unscheduled ileostomy. A total of 300 patients were finally included.

Table 2 shows the characteristic of the patients included, the surgical techniques used and the surgical procedures followed.

Table 2 Patient characteristics and surgical techniques and procedures followed

\begin{tabular}{|c|c|c|}
\hline \multirow{2}{*}{$\begin{array}{c}\text { Patients characteristics }(\mathbf{n}=\mathbf{3 0 0}) \\
\text { Age (years) }\end{array}$} & \multicolumn{2}{|c|}{ Values } \\
\hline & 69 & $35-88$ \\
\hline \multicolumn{3}{|l|}{ Sex } \\
\hline Female & 152 & 51.5 \\
\hline Male & 143 & 48.5 \\
\hline Preoperative stay (days) & 0.82 & 1.93 \\
\hline \multicolumn{3}{|l|}{ Surgical risk: ASA } \\
\hline 1 & 30 & 10.2 \\
\hline$\|$ & 148 & 50.2 \\
\hline III & 117 & 39.7 \\
\hline \multicolumn{3}{|l|}{ Surgical technique } \\
\hline Laparoscopy & 171 & 63.6 \\
\hline Conventional & 98 & 36.4 \\
\hline \multicolumn{3}{|l|}{ Surgical procedure } \\
\hline Right hemicolectomy & 98 & 35.6 \\
\hline Sigmoidectomy & 74 & 26.9 \\
\hline Anterior resection & 67 & 24.4 \\
\hline Left hemicolectomy & 27 & 9.8 \\
\hline Transverse resection & 5 & 1.8 \\
\hline Subtotal colectomy & 4 & 1.5 \\
\hline
\end{tabular}

Quantitative variables are expressed as medians plus minimum and maximum values; qualitative variables are expressed as absolute numbers and percentages. Preoperative stay is expressed as mean and standard deviation.
The median age of the patients was 69 years (35-88); $51.5 \%$ were women (152 patients). The patients were distributed by ASA class as follows: I 10.2\% (30), II $50.2 \%$ (148) and III 39.7\% (117).

Some 63.6\% (171) of the patients underwent laparoscopic surgery and $36.4 \%$ (98) open surgery. Some $15.3 \%$ of the laparoscopically intervened patients required conversion to laparotomy (22).

Sigmoidectomy and right hemicolectomy made up the majority of procedures performed (62.5\%). Some $5.2 \%$ of patients (15) were subjected to preoperative radiotherapy. Laparotomy was medial in $88.8 \%$ and transversal in $11.2 \%$ of patients so intervened.

The mean preoperative hospital stay was 0.82 days (SD: 1.93). The mean duration of surgery was 155.4 min. The median length of time spent in the recovery room was $240 \mathrm{~min}(60-1500)$.

Main features of the protocol and their compliance rates Table 3 shows the compliance rates for the main features outlined in the ERAS protocol, as well as for the other features not explicitly included in the protocol.

Table 3 Compliance with perioperative treatment and postoperative recovery after colon resection within the context of the enhanced recovery program followed

\begin{tabular}{lll}
\hline \multicolumn{3}{l}{ Perioperative treatment variable mentioned in ERAS protocol } \\
\hline \multicolumn{1}{l}{ Number } & Percentage \\
\hline Preoperative & 290 & 99 \\
\hline Perioperative information & 246 & 82.8 \\
\hline No colon preparation & 187 & 65.2 \\
\hline Carbohydrate-rich drinks on day before surgery $^{1}$ & 187 \\
\hline Carbohydrate -rich drinks before surgery $^{2}$ & 182 & \\
\hline Surgery & & \\
\hline Goal directed fluids (Cardio-Q) & \\
\hline No hypothermia & 138 & 46.3 \\
\hline No drainage & 242 & 84.3 \\
\hline Postoperative & 146 & 53.3 \\
\hline No nasogastric tube & & \\
\hline Early mobilisation & 222 & 77.1 \\
\hline Early taking of fluids by mouth & \\
\hline
\end{tabular}

Variable not explicitly mentioned in ERAS protocol

\begin{tabular}{|c|c|c|}
\hline & Number & Percentage \\
\hline Opioid-free pain control ${ }^{5}$ & 206 & 78.3 \\
\hline $\begin{array}{l}\text { Prophylactic medication for nausea and } \\
\text { vomiting }\end{array}$ & 76 & 26.8 \\
\hline Epidural anaesthesia & 106 & 38.8 \\
\hline
\end{tabular}

1: $40.3 \%$ received two, $59.7 \%$ received three or four; $2: 14.8 \%$ received one, $85.2 \%$ received two; 3 : Mean fluid volume received was $1742.5 \mathrm{ml} ; 4: 46.8 \%$ received one, 50\% received two, and $3.2 \%$ received more than two; $5: 42.8 \%$ of patients used patient controlled analgesia. 
The overall compliance to protocol was approximately $65 \%$, but varied widely in its different components.

\section{Postoperative hospital stay and readmission rate}

The median length of postoperative hospital stay was 6 days (3-89 days). Figure 1 shows the distribution of length of postoperative stay. The mean postoperative length of stay according to surgical procedure was: right hemicolectomy and sigmoidectomy 8 days, left hemicolectomy 6 days, and transverse resection and subtotal colectomy 5 days.

Some $2.7 \%$ of the patients (8) were readmitted following discharge for medical or surgical reasons. Three patients re-presented with febrile syndrome, two with nosocomial pneumonia, and three with pulmonary thromboembolism, diarrhoea with hyponatremia or abdominal wall abscess.

Some $7 \%$ of the patients (21) required repeat surgery. The causes included dehiscence (12 patients), fistula or anastomatic leakage (three patients), evisceration (two patients), and abdominal pain, haemoperitoneum, ischemia and intestinal occlusion (one patient each). The median post-repeat-operative length of hospital stay was 6 days (1-20).

\section{Postoperative morbidity/mortality}

Table 4 summarises the complications encountered. The most common were surgical (23.7\% of patients; 71$)$, followed by septic $11 \%$ (33) and other medical complications $9.7 \%$ (29). The most common surgical complications were wound infection $(12 \% ; 36)$, paralytic ileus (10\%; 30; median paralysis time 3 days [2-8]), anastomosis leakage $(4.3 \% ; 13)$ and perioperative haemorrhage $(1.7 \%$; 5$)$. The most common medical

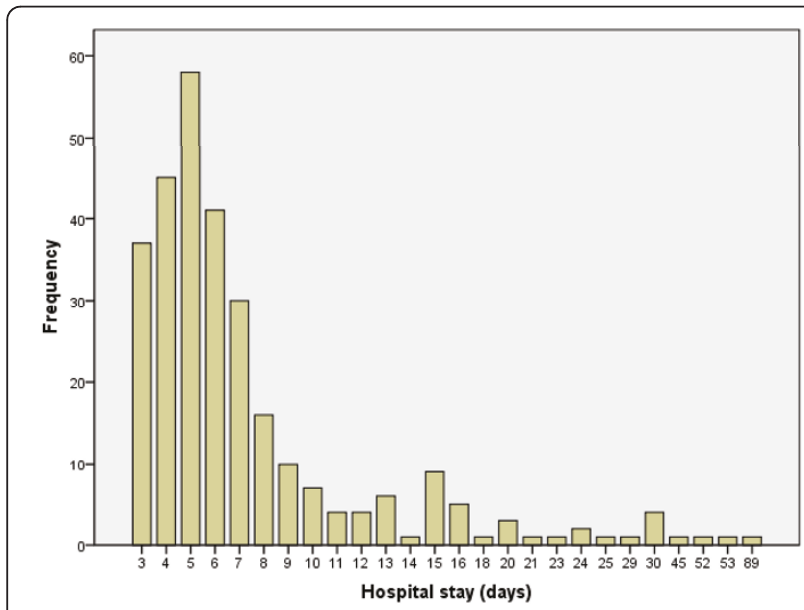

Figure 1 Length of postoperative stay of patients who underwent colon surgery within the context of the present enhanced recovery program.
Table 4 Local and general morbidity following colon resection within the enhanced recovery program followed

\begin{tabular}{|c|c|c|}
\hline Total $(n=300)$ & Number & Percentage \\
\hline Surgical complications & 71 & 23.7 \\
\hline Wound infection & 36 & 12 \\
\hline Paralytic ileus & 30 & 10 \\
\hline Anastomosis leakage & 13 & 4.3 \\
\hline Perioperative haemorrhage & 5 & 1.7 \\
\hline Evisceration & 3 & 1 \\
\hline Perforation & 0 & 0 \\
\hline Other surgical complications & 10 & 3.3 \\
\hline Septic complications & 33 & 11 \\
\hline Abdominal abscess & 13 & 4.3 \\
\hline Urine infection & 11 & 3.7 \\
\hline Respiratory infection & 11 & 3.7 \\
\hline Peritonitis & 7 & 2.3 \\
\hline Sepsis & 3 & 1 \\
\hline Catheter sepsis & 2 & 0.7 \\
\hline Necrotising fascitis & 0 & 0 \\
\hline Other septic complications & 3 & 1 \\
\hline Medical complications & 29 & 9.7 \\
\hline Respiratory distress & 8 & 2.7 \\
\hline Respiratory failure & 8 & 2.7 \\
\hline Cardiac complication & 5 & 1.7 \\
\hline Pulmonary oedema & 3 & 1 \\
\hline Acute urine retention & 3 & 1 \\
\hline Pulmonary embolism & 1 & 0.3 \\
\hline Myocardial infarction & 0 & 0 \\
\hline Cerebrovascular accident & 0 & 0 \\
\hline Venous thrombosis & 0 & 0 \\
\hline Other medical complications & 10 & 3.3 \\
\hline All complications & 89 & 29.7 \\
\hline Mortality & 3 & 1 \\
\hline
\end{tabular}

Note: some patients presented more than one symptom.

complications were respiratory distress $(2.7 \% ; 8)$, respiratory failure $(2.7 \% \% ; 8)$ and cardiac arrhythmia or ischemia $(1.7 \% ; 5)$. Finally, the most common septic complications were abdominal abscess $(4.3 \% ; 13)$, urine infection $(3.7 \% ; 11)$, respiratory infection $(3.7 \% ; 11)$ and peritonitis $(2.3 \%$; 7$)$.

Three patients (1\%), all of whom required repeat surgery, died. Two of these died during their hospital stay due to multi-organ failure and sepsis, and one from cancer following discharge.

\section{Symptoms delaying discharge}

Table 5 records the symptoms that delayed discharge. Some $31.3 \%$ (94) of all patients presented some such 
Table 5 Symptoms delaying discharge

\begin{tabular}{lll}
\hline Total $(\mathbf{n}=\mathbf{3 0 0})$ & Number of patients & Percentage \\
\hline Vomiting or nausea & 36 & 12 \\
\hline Fatigue & 20 & 6.7 \\
\hline Fever of unknown origin & 14 & 4.7 \\
\hline Constipation & 9 & 3 \\
\hline Dizziness & 6 & 2 \\
\hline Pain & 6 & 2 \\
\hline Urine retention & 5 & 1.7 \\
\hline Depression, confusion & 4 & 1.3 \\
\hline Diarrhoea & 3 & 1 \\
\hline Scant diuresis & 3 & 1 \\
\hline Other symptoms & 26 & 8.7 \\
\hline Total & 94 & 31.3 \\
\hline
\end{tabular}

Note: some patients presented more than one symptom.

symptom, 22\% (66) suffered one, 6.3\% (19) suffered two, $2.7 \%$ (8) suffered three, and $0.3 \%$ (1) suffered four. The most common symptoms were vomiting (12\%; 36), dyspnoea $(6.7 \% ; 20)$ and fever of unknown origin $(4.7 \% ; 14)$.

\section{Discussion}

Each of the steps outlined in the present ERAS is based on scientific evidence. For example, patient education is reported to be important in the response to surgery. Now-classic studies [3] have shown that informed patients require less analgesia in the postoperative period and indeed experience significantly less pain than uninformed patients. More recent work has shown that adequate preoperative information reduces patient anxiety before surgery and may also hasten postsurgical recovery $[3,13,14]$.

A number of studies on programmed colon surgery have brought into doubt the need for preoperative mechanical cleansing of the intestine $[3,15]$. The need for strict preoperative fasting has also been recently questioned. Most clinical practice guides suggest a period of absolute fasting of between two and six hours, but recent studies indicate that taking a carbohydraterich drink before surgery may reduce the endocrine catabolic response and improve insulin resistance $[3,16]$, improving surgical results and hastening recovery. The present ERAS included the administration of carbohydrate-rich drinks $(4 \times 200 \mathrm{ml})$ one day prior to surgery plus two further such drinks $(2 \times 200 \mathrm{ml})$ on the morning of surgery. The protocol also included the administration of goal directed fluids made possible by the standard use of oesophageal Doppler monitoring [3,17-21], temperature control to avoid hypothermia [3], and the non-routine use of a nasogastric tube; metaanalyses of several trials suggest the latter may reduce pulmonary complications [3,22]. A further measure was the avoidance of routinely using drainage; several randomised trials have suggested that drainage is of no benefit $[3,23,24]$. Drainage can be avoided in most patients or limited to a short period, facilitating early mobilisation [3], a measure also called for by the ERAS followed. Finally, although taking food orally is commonly limited in the postoperative period, a number of studies have shown that it is safe even after colon surgery involving anastomosis $[3,25,26]$; it was therefore included in the present ERAS.

Additional variables not explicitly included in the ERAS were also measured: use of prophylactic medication for postoperative vomiting and nausea, use of epidural anaesthesia [3], and opioid-free pain control, it has been reported that opioid-free or opioid-reduced analgesia may hasten recovery [3].

When protocols such as the present are implanted, the goal is that there should be full compliance with all measures outlined. However, full compliance is commonly very difficult to achieve [12]. In the present work the overall compliance rate was $65 \%$, but varied widely in its different components. Patients received information in nearly all cases, while compliance with the provision of early postoperative fluids seemed particularly difficult.

The items of the protocol with less compliance were early oral fluid administration, goal-directed fluid therapy and early mobilization. The reason why these items obtained different compliance with the protocol could be the taste of oral fluid, rejection by patients, unavailability of devices and temporary employment of some healthcare providers involved in the ERAS. Probably the implementation could improve involving and training all the professionals who assist the patients included in the protocol and identifying these patients with signboards on bedside.

Missing values were most important for the variable surgical approach with $6.2 \%$ of them, being lower in the other variables.

The rates of complications and mortality recorded were similar to those reported by other authors in randomized controlled trials [5,8-11]. In the present work the most common complication was wound infection. These programmes do not, therefore, appear to place the patient at any extra risk. Our results are similar to previous multicenter studies $[27,28]$ in terms of surgical complications, mortality and readmission rate. The surgical complication rate was $24 \%$ compared to the $14.1 \%$ reported by Schwenk et al [27] and 20\% reported by Braumann et al [28]. The mortality rate was $1 \%$ compared to the $0.8 \%$ reported by Schwenk et al [27] and 0,4\% reported by Braumann et al [28]. The readmission rate was $2.7 \%$ compared to the $3.9 \%$ reported by Schwenk et al [27] and $4 \%$ reported by Braumann et al [28]. 
Finally, the use of the present ERAS was associated with a preoperative hospital stay of fewer than $24 \mathrm{~h}$ and an overall mean stay of 6 days. In other recently published Spanish multicenter study, including data from 50 hospitals, the mean postoperative stay after colorectal resection was 12.36 days [29].

\section{Conclusion}

The present ERAS posed no risk to patients in terms of morbidity, mortality and shortened their hospital stay. The present results show that these programmes can be of benefit to patients and, by reducing hospital costs, may benefit society as a whole.

\section{Acknowledgements}

The authors thank specially to all members of the Spanish working group on fast track surgery: Emilio Maseda, Rafael Uña, Damián García-Olmo (Hospital Universitario La Paz, Madrid, Spain); Carlos Moreno, Marina Manzanera, Francisco A Quezada, Telesfora Sempere (Hospital General La Mancha Centro, Alcázar de San Juan, Spain); Eva Llacer, Carlos Maristany, Arantxa Muñoz, Albert Navarro (Hospital Universitario Mútua Terrassa, Terrassa, Spain); Javier Cerdán, Gonzalo Sanz, Pedro Moral, Fernando Esteban (Hospital Clínico San Carlos, Madrid, Spain); Pablo Royo, Vicente Aguilella, Julia Guillen, Tomás Ruiz, José Cuartero, Mariano Martínez, José M Ramírez (Hospital Clínico Universitario Lozano Blesa, Zaragoza, Spain); Enrique Moncada, Manuel Núñez, Luis C Luna, José E Casal (Hospital Do Meixoeiro, Vigo, Spain); Roger Cabezali, Carlos Emparan, Pablo Soriano, Javier Isla (Fundación Hospital Calahorra, Calahorra, Spain); Antonio Arroyo, Alessandro Garcea, Pilar Serrano, José L Muñoz, Elena Miranda (Hospital General Universitario de Elche, Elche, Spain); José V. Roig, Francisco Villalba, Antonio Salvador, Alfonso Garcia-Fabrique (Hospital General Universitario de Valencia, Valencia, Spain); Luis M Jiménez, Elena Monge, Irene Hidalgo, Emilio Del Valle (Hospital General Universitario Gregorio Marañón, Madrid, Spain); Rafael Morales, José Noguera (Hospital Son Llatzer, Palma de Mallorca, Spain); Xavier Viñas, Enric Macarulla, Victor Murga, Ana Pedregosa (Hospital d'Igualada, Igualada, Spain); Juan A Blasco, Sergio Maeso-Martínez and Daniel Callejo (Health Technology Assessment, Agencia Laín Entralgo, Madrid, Spain). The authors thank Adrian Burton for help with the English language manuscript.

\section{Author details}

'Department of Colorectal Surgery, Hospital Clínico Universitario Lozano Blesa, Zaragoza, Spain. ${ }^{2}$ Health Technology Assessment, Agencia Laín Entralgo, Madrid, Spain. ${ }^{3}$ Department of Surgery, Hospital General Universitario de Valencia, Valencia, Spain. ${ }^{4}$ Department of Surgery, Hospital Do Meixoeiro, Vigo, Spain. ${ }^{5}$ Department of Surgery, Hospital Clínico San Carlos, Madrid, Spain.

\section{Authors' contributions}

Design: JMR, JVR, JEC, FE, JAB, DC and SM.

Data collection: JMR, JVR, JEC and FE.

Data analysing: SM, DC, JAB and JMR.

Writing of manuscript: SM, JAB, JMR and DC.

All authors have read and approve the final manuscript.

\section{Competing interests}

The authors declare that they have no competing interests.

Received: 7 October 2010 Accepted: 14 April 2011

Published: 14 April 2011

\section{References}

1. Schoetz DJ Jr, Bockler M, Rosenblatt MS, Malhotra S, Roberts PL, Murray JJ, Coller JA, Rusin LC: "Ideal" length of stay after colectomy: whose ideal? Dis Colon Rectum 1997, 40:806-810.
2. Kehlet $\mathrm{H}$ : Multimodal approach to control postoperative pathophysiology and rehabilitation. Br J Anaesth 1997, 78:606-617.

3. Kehlet $\mathrm{H}$, Wilmore DW: Multimodal strategies to improve surgical outcome. Am J Surg 2002, 183:630-641.

4. Grol R, Grimshaw J: From best evidence to best practice: effective implementation of change in patients' care. Lancet 2003, 362:1225-1230

5. Anderson AD, McNaught CE, MacFie J, Tring I, Barker P, Mitchell CJ: Randomized clinical trial of multimodal optimization and standard perioperative surgical care. Br J Surg 2003, 90:1497-1504.

6. Delaney CP, Fazio WW, Senagore AJ, Robinson B, Halverson AL, Remzi FH: 'Fast track' postoperative management protocol for patients with high co-morbidity undergoing complex abdominal and pelvic colorectal surgery. Br J Surg 2001, 88:1533-1538.

7. Kehlet $H$, Mogensen $T$ : Hospital stay of 2 days after open sigmoidectomy with a multimodal rehabilitation programme. Br J Surg 1999, 86:227-230.

8. Stephen $A E$, Berger DL: Shortened length of stay and hospital cost reduction with implementation of an accelerated clinical care pathway after elective colon resection. Surgery 2003, 133:277-282

9. Delaney CP, Zutshi M, Senagore AJ, Remzi FH, Hammel J, Fazio WW: Prospective, randomized, controlled trial between a pathway of controlled rehabilitation with early ambulation and diet and traditional postoperative care after laparotomy and intestinal resection. Dis Colon Rectum 2003, 46:851-859.

10. Gatt M, Anderson AD, Reddy BS, Hayward-Sampson P, Tring IC, MacFie J: Randomized clinical trial of multimodal optimization of surgical care in patients undergoing major colonic resection. Br J Surg 2005, 92:1354-1362.

11. Khoo CK, Vickery CJ, Forsyth N, Vinall NS, Eyre-Brook IA: A prospective randomized controlled trial of multimodal perioperative management protocol in patients undergoing elective colorectal resection for cancer. Ann Surg 2007, 245:867-872.

12. Maessen J, Dejong CH, Hausel J, Nygren J, Lassen K, Andersen J, Kessels AG, Revhaug A, Kehlet $H$, Ljungqvist $O$, et al: A protocol is not enough to implement an enhanced recovery programme for colorectal resection. $\mathrm{Br}$ J Surg 2007, 94:224-231.

13. Daltroy LH, Morlino $\mathrm{Cl}$, Eaton $\mathrm{HM}$, Poss R, Liang $\mathrm{MH}$ : Preoperative education for total hip and knee replacement patients. Arthritis Care Res 1998, 11:469-478.

14. Klafta JM, Roizen MF: Current understanding of patients' attitudes toward and preparation for anesthesia: a review. Anesth Analg 1996, 83:1314-1321.

15. Burke P, Mealy K, Gillen $\mathrm{P}$, Joyce W, Traynor $\mathrm{O}$, Hyland J: Requirement for bowel preparation in colorectal surgery. Br J Surg 1994, 81:907-910.

16. Nygren J, Soop M, Thorell A, Sree NK, Ljungqvist O: Preoperative oral carbohydrates and postoperative insulin resistance. Clin Nutr 1999, 18:117-120.

17. Conway DH, Mayall R, bdul-Latif MS, Gilligan S, Tackaberry C: Randomised controlled trial investigating the influence of intravenous fluid titration using oesophageal Doppler monitoring during bowel surgery. Anaesthesia 2002, 57:845-849.

18. Gan TJ, Soppitt A, Maroof M, el-Moalem H, Robertson KM, Moretti E, Dwane P, Glass PS: Goal-directed intraoperative fluid administration reduces length of hospital stay after major surgery. Anesthesiology 2002, 97:820-826.

19. Mowatt G, Houston G, Hernandez R, de VR, Fraser C, Cuthbertson B, Vale L: Systematic review of the clinical effectiveness and cost-effectiveness of oesophageal Doppler monitoring in critically ill and high-risk surgical patients. Health Technol Assess 2009, 13:1-118

20. Noblett SE, Snowden CP, Shenton BK, Horgan AF: Randomized clinical trial assessing the effect of Doppler-optimized fluid management on outcome after elective colorectal resection. Br J Surg 2006, 93:1069-1076.

21. Wakeling HG, McFall MR, Jenkins CS, Woods WG, Miles WF, Barclay GR, Fleming SC: Intraoperative oesophageal Doppler guided fluid management shortens postoperative hospital stay after major bowel surgery. Br J Anaesth 2005, 95:634-642.

22. Cheatham ML, Chapman WC, Key SP, Sawyers JL: A meta-analysis of selective versus routine nasogastric decompression after elective laparotomy. Ann Surg 1995, 221:469-476.

23. Merad F, Yahchouchi E, Hay JM, Fingerhut A, Laborde $Y$, Langlois-Zantain O: Prophylactic abdominal drainage after elective colonic resection and suprapromontory anastomosis: a multicenter study controlled by 
randomization. French Associations for Surgical Research. Arch Surg 1998, 133:309-314.

24. Urbach DR, Kennedy ED, Cohen MM: Colon and rectal anastomoses do not require routine drainage: a systematic review and meta-analysis. Ann Surg 1999, 229:174-180.

25. Carr CS, Ling KD, Boulos P, Singer M: Randomised trial of safety and efficacy of immediate postoperative enteral feeding in patients undergoing gastrointestinal resection. BMJ 1996, 312:869-871.

26. Di Fronzo LA, Cymerman J, O'Connell TX: Factors affecting early postoperative feeding following elective open colon resection. Arch Surg 1999, 134:941-945

27. Schwenk W, Gunther N, Wendling P, Schmid M, Probst W, Kipfmuller K, Rumstadt B, Walz MK, Engemann R, Junghans T: "Fast-track" rehabilitation for elective colonic surgery in Germany-prospective observational data from a multi-centre quality assurance programme. Int I Colorectal Dis 2008, 23:93-99.

28. Braumann C, Guenther N, Wendling P, Engemann R, Germer CT, Probst W, Mayer HP, Rehnisch B, Schmid M, Nagel K, Schwenk W, Fast-Track Colon II Quality Assurance Group: Multimodal perioperative rehabilitation in elective conventional resection of colonic cancer: results from the German Multicenter Quality Assurance Program 'Fast-Track Colon II'. Dig Surg 2009, 26:123-9.

29. Rodríguez-Cuellar E, Ruiz López P, Romero Simó M, Landa García Jl, Roig Vila JV, Ortiz Hurtado H: Analysis of the quality of surgical treatment of colorectal cancer, in 2008. A national study. Cir Esp 2010, 88:238-46.

Pre-publication history

The pre-publication history for this paper can be accessed here: http://www.biomedcentral.com/1471-2482/11/9/prepub

doi:10.1186/1471-2482-11-9

Cite this article as: Ramírez et al.: Enhanced recovery in colorectal

surgery: a multicentre study. BMC Surgery 2011 11:9.

\section{Submit your next manuscript to BioMed Central and take full advantage of:}

- Convenient online submission

- Thorough peer review

- No space constraints or color figure charges

- Immediate publication on acceptance

- Inclusion in PubMed, CAS, Scopus and Google Scholar

- Research which is freely available for redistribution

Submit your manuscript at www.biomedcentral.com/submit 